https://doi.org/10.15407/ujpe65.1.61

V.V. BOBKOV, L.P. TISHCHENKO, YU.I. KOVTUNENKO, R.I. STAROVOYTOV, YU.E. LOGACHEV, A.B. TSAPENKO, L.A. GAMAYUNOVA

V.N. Karazin National University of Kharkiv

(31, Kurchatov Ave., Kharkiv 61108, Ukraine; e-mail: plip@karazin.ua)

\title{
IMPLANTATION OF DEUTERIUM \\ AND HELIUM IONS INTO A TUNGSTEN-COATED COMPOSITE STRUCTURE
}

\begin{abstract}
The capture, retention, and thermal desorption of deuterium and helium ions with medium energies implanted into tungsten-coated multilayer functional structures and the formation of corresponding radiation-induced damages in the crystal lattice of the tungsten coatings of those structures have been studied making use of the thermal desorption spectroscopy and electron microscopy methods. The behavior of deuterium and helium in the examined materials and its dependence on the post-implantation heating temperature, the dose of irradiation with $D^{+}$ and $\mathrm{He}^{+}$ions, and the irradiation condition - separate (making use of ions of only one kind) or sequential (making use of ions of both kinds) - are analyzed. A classification of radiationinduced defects and mechanisms of their annealing are proposed.

Ke ywords: radiation-induced defects, deuterium, helium, ion implantation, thermal desorption, tungsten coating, composite materials.
\end{abstract}

\section{Introduction}

The processes of capture, retention, and release of hydrogen and helium isotopes, as well as changes in the structure of the surface layer of materials used in the devices of modern nuclear fusion installations, which emerge owing to the interaction of plasma with the surface of those materials, are a matter of interest to the designers of fusion reactors. The study of those processes under laboratory conditions with the help of deuterium and helium beams makes it possible to obtain parameters characterizing the behavior of mentioned gases in solids and to study the corresponding radiation-induced damages. Tungsten (W), which is applied as a vacuum-deposited coating of multilayer functional structures, is one of the most

(C) V.V. BOBKOV, L.P. TISHCHENKO, YU.I. KOVTUNENKO, R.I. STAROVOYTOV, YU.E. LOGACHEV, A.B. TSAPENKO, L.A. GAMAYUNOVA, 2020

ISSN 2071-0194. Ukr. J. Phys. 2020. Vol. 65, No. 1 promising materials intended to be used in contact with plasma in thermonuclear facilities $[1,2]$. It has a low sputtering ratio, enhanced thermal stability, and, what is especially important, a low capture efficiency of hydrogen isotopes, so that it is characterized by an insignificant tritium accumulation.

Researches [1-26] dealing with the accumulation of deuterium and helium and their thermal desorption into vacuum $[1-4,7,8,11]$, the distribution of those gases over the specimen depth $[5,6]$, and the formation of structural damages in the near-surface layers $[3,4,7-10,12]$ were mainly performed using tungsten foils rather than vacuum-deposited tungsten coatings. Most of the works were carried out by separately implanting $\mathrm{D}^{+}$or $\mathrm{He}^{+}$ions into the $\mathrm{W}$ foil $[1,3-$ 12]. Only a small number of works were performed using the sequential implantation of those ions $[8,13$ 18]. The researches concerning the processes that accompany the implantation of $\mathrm{D}^{+}$or $\mathrm{He}^{+}$ions into vacuum-deposited tungsten coatings and the behav- 
ior of deuterium and helium in them are not numerous [19-26]. Moreover, no results of researches with the sequential implantation of those ions into the indicated coatings were found in the literature.

This work continues our researches [27-30] dealing with the formation and annealing of radiationinduced defects, the interaction of the intrinsic and induced matrix defects with the implanted ion-beam particles, and the changes in the microstructure of the surface layer and the surface morphology of the specimens irradiated with medium-energy hydrogen and helium isotopes. In particular, the processes that accompany the implantation of $\mathrm{D}^{+}$and $\mathrm{He}^{+}$ions into tungsten coatings in multilayer functional structures that are proposed to be applied in devices of thermonuclear facilities are studied. The formation of radiation-induced damages in the crystal lattice of the coating, as well as the capture, retention, and thermal desorption of ion-implanted deuterium and helium into vacuum, is considered. The behavior of deuterium and helium in irradiated specimens is analyzed for various post-implantation heating temperatures, $\mathrm{He}^{+}$and $\mathrm{D}^{+}$irradiation doses, and ion irradiation scenarios: separate (i.e. when ions of only one kind are used) or sequential (when ions of both kinds are applied after each other). Possible types of emerging radiation defects and the mechanisms of their annealing are proposed.

\section{Research Technique}

Tungsten coatings $1 \mu \mathrm{m}$ in thickness are studied. They were obtained by the magnetron sputtering of a $\mathrm{W}$ target in the Ar atmosphere at a pressure of 1.0 Pa. Tungsten was deposited at the temperature $T=600 \mathrm{~K}$ and at a rate of $0.6 \mathrm{~nm} / \mathrm{s}$ onto a $0.5-\mathrm{mm}$ stainless steel (SS) substrate covered with a sputtered intermediate Ti layer narrower than $10 \mathrm{~nm}$. The tungsten coatings had a polycrystalline structure with an average grain size of about $60 \mathrm{~nm}$. The specimens were designated as $\mathrm{SS}+\mathrm{W}(\mu \mathrm{m})$. The thickness of the stainless steel substrate in our experiments was dictated by a necessity to heat up the specimens to $1800 \mathrm{~K}$ at a predetermined rate.

The specimens were separately irradiated at room temperature making use of $20-\mathrm{keV} \mathrm{He}^{+}$-ion beams with a current density of about $5 \mu \mathrm{A} / \mathrm{cm}^{2}$ to doses within an interval of $1.0 \times 10^{17} \mathrm{~cm}^{-2} \leq \Phi_{\mathrm{He}^{+}} \leq$ $\leq 35.5 \times 10^{+17} \mathrm{~cm}^{-2}$ or with the help of $10-\mathrm{keV} \mathrm{D}^{+}$ ion beams (using $20-\mathrm{keV} \mathrm{D}_{2}^{+}$ions) with a current density of about $5 \mu \mathrm{A} / \mathrm{cm}^{2}$ to doses within an interval of $0.2 \times 10^{17} \mathrm{~cm}^{-2} \leq \Phi_{\mathrm{D}^{+}} \leq 16.5 \times 10^{17} \mathrm{~cm}^{-2}$. For the energies used in this work, the penetration depths of the helium and deuterium atoms, as well as the distribution depth of radiation damages induced in the $\mathrm{W}$ crystalline lattice by $\mathrm{He}^{+}$and $\mathrm{D}^{+}$ions, are much smaller than the $\mathrm{W}$ coating thickness.

The sequential irradiation of similar specimens with $\mathrm{He}^{+}$and $\mathrm{D}^{+}$ions was carried out in both the scenarios $\mathrm{He}^{+} \rightarrow \mathrm{D}^{+}$and $\mathrm{D}^{+} \rightarrow \mathrm{He}^{+}$keeping the same values of the ion energy, beam current density, and specimen temperature. The irradiation doses were within intervals of $1.03 \times 10^{17} \mathrm{~cm}^{-2} \leq \Phi_{\mathrm{He}^{+}} \leq 4.0 \times$ $\times 10^{17} \mathrm{~cm}^{-2}$ for $\mathrm{He}^{+}$ions and $0.15 \times 10^{17} \mathrm{~cm}^{-2} \leq$ $\leq \Phi_{\mathrm{D}^{+}} \leq 4.6 \times 10^{17} \mathrm{~cm}^{-2}$ for $\mathrm{D}^{+}$ones.

Before the irradiation of examined specimens with ions of another kind, the ion source in the installation was trained under a residual vacuum. In so doing, the beam currents of ions with masses corresponding to the ions used at the previous stage of the experiment and the ions planned to be used at the next stage were measured with the help of a Faraday cylinder. At the initial vacuum training, there was no specimen in the installation. Later, during a series of experiments, when the specimen got increasing irradiation doses of ions of the same kind, it was shielded with a screen at the vacuum training. The specimen training continued until the values of the controlled currents of ion beams reached the background values. Afterward, the working gas was let into the ion source by means of an inlet system, the operating parameters of the ion beam were set, and the screen was removed from the specimen in a vacuum chamber. When changing the working gas, the training of an ion source was carried out simultaneously with the vacuum training of the gas inlet system. The mass spectrometric control of the composition of the residual gas environment was performed at that. This method of preparation of the installation made it possible to exclude the presence of deuterium (helium) impurities in the helium (deuterium) beams in the experiments described in this paper.

Figure 1 demonstrates the distribution profiles of deuterium (1) and helium (2) atoms in the specimen depth and the profiles of the displacements of matrix atoms ( 3 for $\mathrm{D}^{+}$ions and 4 for $\mathrm{He}^{+}$ions) also into the specimen depth, which were calculated using the SRIM program described in work [31]. According to

ISSN 2071-0194. Ukr. J. Phys. 2020. Vol. 65, No. 1 
the calculation results, the mean projective and total path lengths of $\mathrm{D}^{+}(10 \mathrm{keV})$ and $\mathrm{He}^{+}(20 \mathrm{keV})$ ions in the tungsten coating were approximately equal to 60 and $160 \mathrm{~nm}$, respectively. They were much shorter than the coating thickness. The profiles of radiationinduced damages created by $\mathrm{D}^{+}$and $\mathrm{He}^{+}$ions in the $\mathrm{W}$ crystal lattice were identical, being located in the ion-implanted zone (see curves 3 and 4, respectively).

In order to study the accumulation processes of helium and deuterium ion-implanted into tungstencoated composite structures, their gas release into vacuum, as well as the formation and annealing of the radiation-induced defects in the matrix and their interaction with one another, such methods as the thermal desorption spectrometry (TDS), transmission electron microscopy (TEM), and reflection electron microscopy (REM) were used. In particular, the TDS method was applied to obtain thermal desorption spectra of helium and deuterium $(m=4 \mathrm{amu})$ with the help of a gas mass spectrometer PTI-7A calibrated with the use of a HELIT-1 helium leak, as well as the data [32] on the ionization cross-sections of helium and deuterium particles in the source of a given spectrometer. The concentration $C$ and the capture efficiency $\eta=C / \Phi$ of implanted gases were also calculated. The more detailed description of the experimental technique can be found in work [33].

The thermal desorption spectra of helium atoms and deuterium molecules were studied when the irradiated specimens were heated up within a temperature interval of $290-1800 \mathrm{~K}$ at the constant rate $\alpha=0.8 \mathrm{~K} / \mathrm{s}$. The heated specimens were arranged on a Ta ribbon with a chromel-alumel thermocouple welded to the latter. The spectra describe the number $S$ of implanted gas particles that were released at a given heating temperature $T$ as a function of this temperature. The methodological error of temperature determination was $\pm 25 \mathrm{~K}$. The sensitivity of the method used to determine the amount of helium and deuterium particles was not worse than $2 \times 10^{12} \mathrm{~cm}^{-2}$. When the irradiated specimens were heated in a temperature interval of $290-1800 \mathrm{~K}$, the partial pressure of helium or deuterium did not exceed $1 \times 10^{-9} \mathrm{~Pa}$.

Since the mass spectrometry measurements of the thermal desorption of deuterium and helium were carried out by measuring the current intensities of $\mathrm{D}^{+}$ and $\mathrm{He}^{+}$ions (both have the mass $m=4 \mathrm{amu}$ ), it was necessary to establish criteria that would allow the

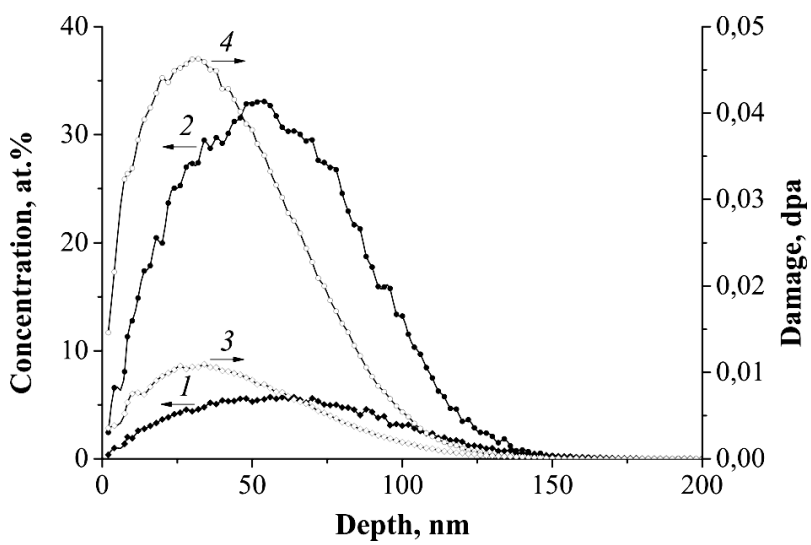

Fig. 1. Distribution profiles of deuterium (1) and helium (2) atoms in the $\mathrm{W}$ coating depth, and the profiles of the matrix atom shifts from the lattice sites for $\mathrm{D}^{+}(3)$ and $\mathrm{He}^{+}(4)$ ions calculated using the SRIM program for $\mathrm{W}$ irradiated with $\mathrm{D}^{+}$ $\left(10 \mathrm{keV}, \Phi_{\mathrm{D}^{+}}=4.0 \times 10^{17} \mathrm{~cm}^{-3}, \eta_{\mathrm{D}}=0.1\right)$ and $\mathrm{He}^{+}(20 \mathrm{keV}$, $\left.\Phi_{\mathrm{He}^{+}}=2.0 \times 10^{17} \mathrm{~cm}^{-3}, \eta_{\mathrm{He}}=0.8\right)$ ions

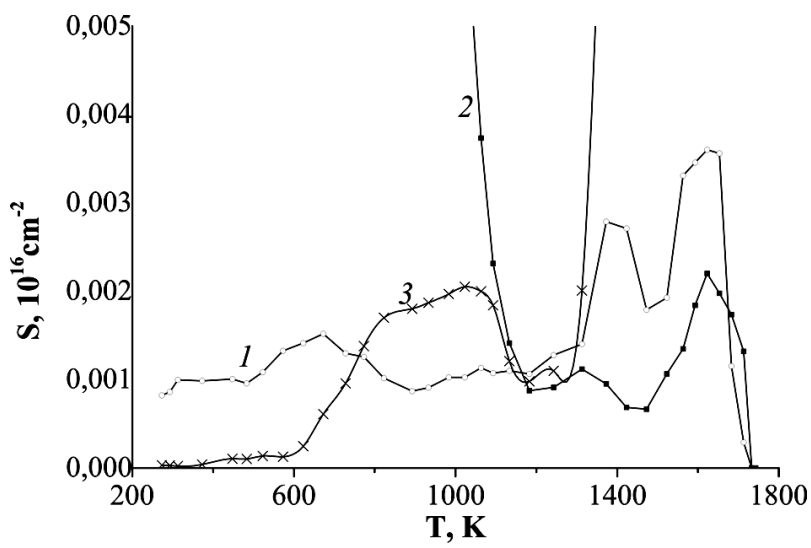

Fig. 2. Dependences of the quantity $S$ for particles with $m=4$ amu on the heating temperature of $\mathrm{SS}+\mathrm{W}(\mu \mathrm{m})$ specimens: (1) non-irradiated, (2) irradiated with $\mathrm{D}^{+}$ions $(10 \mathrm{keV}$, $\Phi_{\mathrm{D}^{+}}=4.0 \times 10^{17} \mathrm{~cm}^{-3}$ ), and (3) irradiated with $\mathrm{He}^{+}$ions $\left(20 \mathrm{keV}, \Phi_{\mathrm{He}^{+}}=2.0 \times 10^{17} \mathrm{~cm}^{-3}\right) . \alpha=0.8 \mathrm{~K} / \mathrm{s}$

desorption of each gas to be interpreted correctly. For particles with $m=4 \mathrm{amu}$, the dependences of the quantity $S$ on the specimen heating temperature are shown in Fig. 2: for non-irradiated specimens (1) and for specimens irradiated with $\mathrm{D}^{+}$(2) or $\mathrm{He}^{+}$(3) ions. From curve 1, one can see that the background of particles with $m=4 \mathrm{amu}$ did not exceed a value.of $0.001 \times 10^{16} \mathrm{~cm}^{-2}$ at temperatures $T<1200 \mathrm{~K}$ and $0.005 \times 10^{16} \mathrm{~cm}^{-2}$ in the temperature interval $\Delta T=1600 \div 1800 \mathrm{~K}$, where the evaporation of the components from the rear side of the stainless steel 


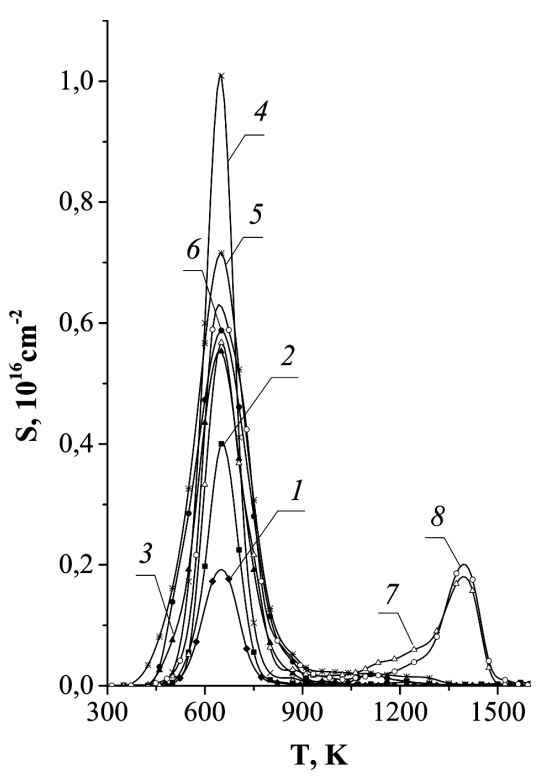

Fig. 3. Thermal desorption spectra of deuterium from a tungsten coating of the $\mathrm{SS}+\mathrm{W}(\mu \mathrm{m})$ composite structure irradiated with $\mathrm{D}^{+}$ions to various doses $\Phi_{\mathrm{D}^{+}}=1.0 \times 10^{17} \mathrm{~cm}^{-2}$ (1), $2.0 \times 10^{17} \mathrm{~cm}^{-2}(2), 3.0 \times 10^{17} \mathrm{~cm}^{-2}$ (3), $4.0 \times 10^{17} \mathrm{~cm}^{-2}$ (4), $5.0 \times 10^{17} \mathrm{~cm}^{-2}(5), 7.0 \times 10^{17} \mathrm{~cm}^{-2}(6), 10.0 \times 10^{17} \mathrm{~cm}^{-2}$ (7), and $16.5 \times 10^{17} \mathrm{~cm}^{-2}(8)$. The ion energy is $10 \mathrm{keV}$, $\alpha=0.8 \mathrm{~K} / \mathrm{s}$

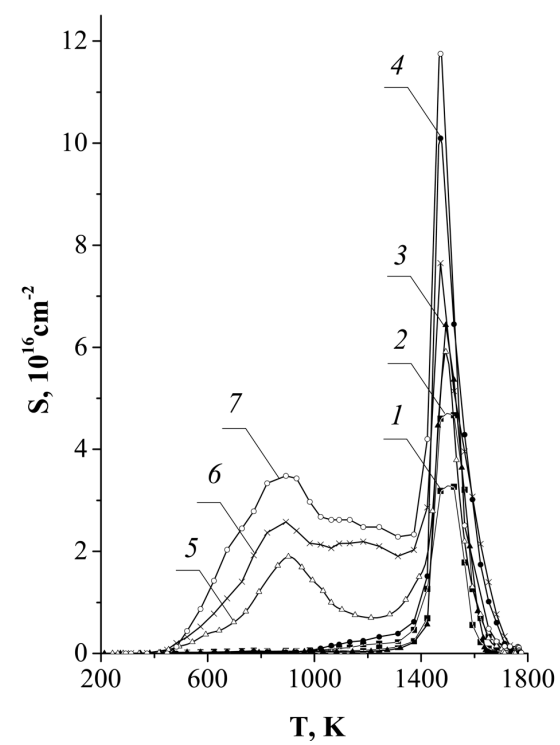

Fig. 4. Thermal desorption spectra of helium from a tungsten coating of the $\mathrm{SS}+\mathrm{W}(\mu \mathrm{m})$ composite structure irradiated with $\mathrm{He}^{+}$ions to various doses $\Phi_{\mathrm{He}^{+}}=1.0 \times 10^{17} \mathrm{~cm}^{-2}(1), 2.0 \times$ $\times 10^{17} \mathrm{~cm}^{-2}$ (2), $3.1 \times 10^{17} \mathrm{~cm}^{-2}$ (3), $4.0 \times 10^{17} \mathrm{~cm}^{-2}$ (4), $4.7 \times 10^{17} \mathrm{~cm}^{-2}(5), 8.3 \times 10^{17} \mathrm{~cm}^{-2}(6)$, and $35.5 \times 10^{17} \mathrm{~cm}^{-2}$ (7). The ion energy is $20 \mathrm{keV}, \alpha=0.8 \mathrm{~K} / \mathrm{s}$ substrate and an insignificant increase of the final vacuum in the chamber were observed. In the thermal desorption spectra of helium or deuterium implanted separately to the sequential irradiation doses quoted in Table, the value of $S$ does not exceed its background value at $T<1200 \mathrm{~K}$ for helium (3) and at $T \geq 1200 \mathrm{~K}$ for deuterium (2). This fact allows a supposition to be made that the thermal desorption spectra of helium and deuterium, whose ions are sequentially implanted in different orders, reflect the release of $\mathrm{D}_{2}$ from the tungsten coating into vacuum at $T<1200 \mathrm{~K}$ and the release of He at $T \geq 1200 \mathrm{~K}$.

The changes in the microstructure of the surface layer of a tungsten coating containing implanted helium or deuterium were studied on a transmission electron microscope EVM-100L using thinner specimens. The surface morphology of irradiated specimens was monitored on a scanning electron microscope REM-100U.

\section{Experimental Results and Discussion}

\subsection{Study of regularities}

in the accumulation of ion-implanted

deuterium and helium in and their

thermal desorption from tungsten coatings of composite structures

3.1. Separate irradiation of tungsten

coatings with deuterium and helium ions

When the experimental specimens with implanted deuterium or helium were heated up, the thermally stimulated release of the latter from the tungsten coatings into vacuum was observed. Figure 3 exhibits the thermal desorption spectra of deuterium from the coating in the case of the $\mathrm{SS}+\mathrm{W}(\mu \mathrm{m})$ composite structure irradiated with $\mathrm{D}^{+}$ions to various doses. The thermal desorption spectra of helium from the tungsten coating of an identical composite structure, but irradiated with $\mathrm{He}^{+}$ions to various doses, are shown in Fig. 4. The limits of the temperature intervals $\Delta T$ in which deuterium and helium are thermally released and the character of their thermal desorption spectra depend, for the given material, on the type of implanted gases and the dose of irradiation with $\mathrm{D}^{+}$and $\mathrm{He}^{+}$ions. The limits of the temperature intervals $\Delta T$ and the temperatures $T_{\max }$ corresponding to the maxima of the peaks in the thermal desorption spectra are quoted in Table.

ISSN 2071-0194. Ukr. J. Phys. 2020. Vol. 65, No. 1 
Parameters of the deuterium and helium captures

in and their thermal desorption from a W coating of the $\mathrm{SS}+\mathrm{W}(\mu \mathrm{m})$ composite system

\begin{tabular}{|c|c|c|c|c|c|c|c|c|c|c|c|}
\hline \multirow{2}{*}{$\begin{array}{l}\text { Irradiation } \\
\text { scenario }\end{array}$} & \multicolumn{2}{|c|}{$\Phi, 10^{17} \mathrm{~cm}^{-2}$} & \multicolumn{2}{|c|}{$C, 10^{17} \mathrm{~cm}^{-2}$} & \multicolumn{2}{|c|}{$\eta, \pm 10 \%$} & \multirow{2}{*}{$\Delta T, \mathrm{~K}$} & \multirow{2}{*}{\multicolumn{4}{|c|}{$T_{\max }, \mathrm{K}$}} \\
\hline & $\mathrm{D}^{+}$ & $\mathrm{He}^{+}$ & $\mathrm{D}$ & $\mathrm{He}$ & $\mathrm{D}$ & $\mathrm{He}$ & & & & & \\
\hline $\mathrm{He}^{+}$ & & 1.0 & & 0.80 & & 0.80 & $900-1750$ & & 1500 & & \\
\hline $\mathrm{He}^{+}$ & & 2.0 & & 1.64 & & 0.82 & $900-1750$ & & 1500 & & \\
\hline $\mathrm{He}^{+}$ & & 3.06 & & 2.55 & & 0.83 & $900-1750$ & & 1500 & & \\
\hline $\mathrm{He}^{+}$ & & 4.0 & & 3.16 & & 0.79 & $900-1750$ & & 1490 & & \\
\hline $\mathrm{He}^{+}$ & & 4.7 & & 3.59 & & 0.76 & $480-1750$ & & 1490 & & 900 \\
\hline $\mathrm{He}^{+}$ & & 6.1 & & 4.36 & & 0.71 & $450-1750$ & & 1500 & & 900 \\
\hline $\mathrm{He}^{+}$ & & 8.3 & & 5.3 & & 0.65 & $450-1750$ & & 1480 & & 900 \\
\hline $\mathrm{He}^{+}$ & & 10 & & 6.0 & & 0.60 & $450-1750$ & & 1490 & 1000 & 900 \\
\hline $\mathrm{He}^{+}$ & & 16 & & 6.72 & & 0.42 & $350-1750$ & & 1480 & 1200 & 900 \\
\hline $\mathrm{He}^{+}$ & & 35.5 & & 6.96 & & 0.2 & $350-1750$ & & 1500 & 1200 & 900 \\
\hline $\mathrm{D}^{+}$ & 0.2 & & 0.026 & & 0.13 & & $380-960$ & 640 & & & \\
\hline $\mathrm{D}^{+}$ & 1.0 & & 0.12 & & 0.12 & & $380-960$ & 640 & & & \\
\hline $\mathrm{D}^{+}$ & 2.0 & & 0.25 & & 0.13 & & $380-960$ & 640 & & & \\
\hline $\mathrm{D}^{+}$ & 2.5 & & 0.32 & & 0.13 & & $380-960$ & 640 & & & \\
\hline $\mathrm{D}^{+}$ & 3.0 & & 0.394 & & 0.13 & & $380-960$ & 640 & & & \\
\hline $\mathrm{D}^{+}$ & 4.0 & & 0.476 & & 0.12 & & $380-960$ & 640 & & & \\
\hline $\mathrm{D}^{+}$ & 5.0 & & 0.5 & & 0.10 & & $350-1000$ & 645 & & & \\
\hline $\mathrm{D}^{+}$ & 7.0 & & 0.526 & & 0.08 & & $350-1000$ & 645 & & & \\
\hline $\mathrm{D}^{+}$ & 10.0 & & 0.62 & & 0.06 & & $300-1580$ & 640 & 1400 & & \\
\hline $\mathrm{D}^{+}$ & 16.5 & & 0.7 & & 0.04 & & $300-1580$ & 640 & 1380 & & \\
\hline $\mathrm{D}^{+} \rightarrow \mathrm{He}^{+}$ & 2.0 & 1.03 & 0.24 & 0.85 & 0.12 & 0.83 & $380-1750$ & 640 & 1480 & & \\
\hline $\mathrm{D}^{+} \rightarrow \mathrm{He}^{+}$ & 2.0 & 2.0 & 0.24 & 1.68 & 0.12 & 0.84 & $370-1750$ & 640 & 1480 & & \\
\hline $\mathrm{D}^{+} \rightarrow \mathrm{He}^{+}$ & 2.0 & 3.03 & 0.26 & 2.35 & 0.13 & 0.78 & $370-1750$ & 640 & 1520 & & \\
\hline $\mathrm{D}^{+} \rightarrow \mathrm{He}^{+}$ & 2.0 & 4.0 & 0.24 & 3.12 & 0.12 & 0.78 & $370-1750$ & 640 & 1520 & & \\
\hline $\mathrm{He}^{+} \rightarrow \mathrm{D}^{+}$ & 2.0 & 1.03 & 0.24 & 0.84 & 0.12 & 0.82 & $380-1750$ & 640 & 1480 & & \\
\hline $\mathrm{He}^{+} \rightarrow \mathrm{D}^{+}$ & 2.0 & 2.0 & 0.26 & 1.58 & 0.13 & 0.79 & $370-1750$ & 640 & 1480 & & \\
\hline $\mathrm{He}^{+} \rightarrow \mathrm{D}^{+}$ & 2.0 & 3.0 & 0.24 & 2.43 & 0.12 & 0.81 & $370-1750$ & 640 & 1520 & & \\
\hline $\mathrm{He}^{+} \rightarrow \mathrm{D}^{+}$ & 2.0 & 4.0 & 0.26 & 3.05 & 0.13 & 0.76 & $370-1750$ & 640 & 1520 & & \\
\hline $\mathrm{D}^{+} \rightarrow \mathrm{He}^{+}$ & 0.15 & 2.0 & 0.019 & 1.68 & 0.13 & 0.84 & $380-1700$ & 645 & 1500 & & \\
\hline $\mathrm{D}^{+} \rightarrow \mathrm{He}^{+}$ & 0.8 & 2.0 & 0.1 & 1.64 & 0.13 & 0.84 & $380-1700$ & 640 & 1500 & & \\
\hline $\mathrm{D}^{+} \rightarrow \mathrm{He}^{+}$ & 2.0 & 2.0 & 0.24 & 1.68 & 0.12 & 0.84 & $370-1750$ & 640 & 1480 & & \\
\hline $\mathrm{D}^{+} \rightarrow \mathrm{He}^{+}$ & 4.6 & 2.0 & 0.59 & 1.65 & 0.13 & 0.83 & $380-1760$ & 640 & 1520 & & \\
\hline $\mathrm{He}^{+} \rightarrow \mathrm{D}^{+}$ & 0.2 & 2.0 & 0.026 & 1.66 & 0.13 & 0.83 & $380-1700$ & 645 & 1500 & & \\
\hline $\mathrm{He}^{+} \rightarrow \mathrm{D}^{+}$ & 2.0 & 2.0 & 0.26 & 1.58 & 0.13 & 0.79 & $370-1750$ & 640 & 1480 & & \\
\hline $\mathrm{He}^{+} \rightarrow \mathrm{D}^{+}$ & 3.4 & 2.0 & 0.424 & 1.62 & 0.13 & 0.81 & $380-1750$ & 640 & 1520 & & \\
\hline
\end{tabular}

As one can see from Fig. 3, the appreciable release of deuterium from the tungsten coating began at the temperatures $T \geq 350 \mathrm{~K}$ and terminated at $T \approx 1000 \mathrm{~K}$ (curves 1 to 6 ) for specimens irradiated ISSN 2071-0194. Ukr. J. Phys. 2020. Vol. 65, No. 1 to the doses $\Phi_{\mathrm{D}^{+}} \leq 7.0 \times 10^{17} \mathrm{~cm}^{-2}$. For specimens irradiated to $\Phi_{\mathrm{D}^{+}} \geq 10.0 \times 10^{17} \mathrm{~cm}^{-2}$, the insignificant release of $\mathrm{D}_{2}$ also took place in the temperature interval $\Delta T=1000 \div 1580 \mathrm{~K}$ (curves 7 and 8 ). The 


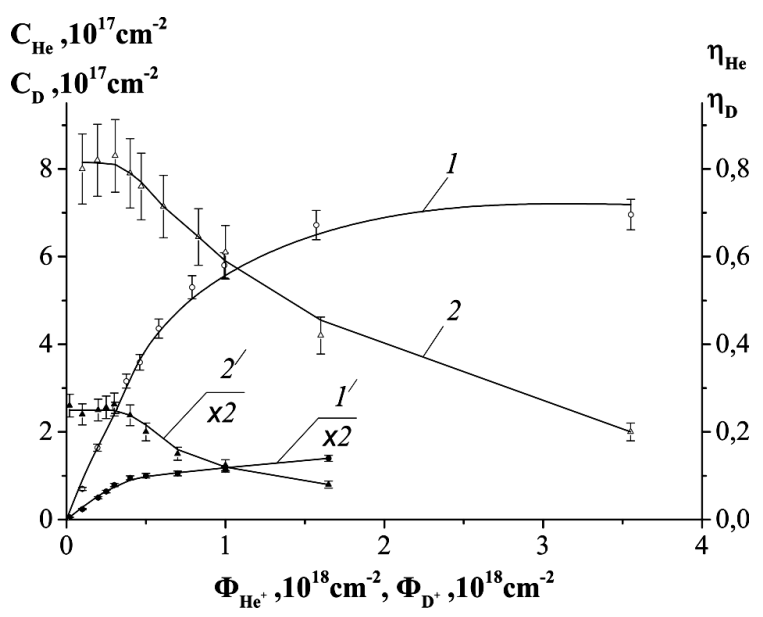

Fig. 5. Dependences $C_{\mathrm{He}}\left(\Phi_{\mathrm{He}^{+}}\right)(1), C_{\mathrm{D}}\left(\Phi_{\mathrm{D}^{+}}\right) \quad\left(1^{\prime}\right)$, $\eta_{\mathrm{He}}\left(\Phi_{\mathrm{He}^{+}}\right)(2)$, and $\eta_{\mathrm{D}}\left(\Phi_{\mathrm{D}^{+}}\right)\left(2^{\prime}\right)$ for helium and deuterium in a tungsten coating of the $\mathrm{SS}+\mathrm{W}(\mu \mathrm{m})$ composite structure irradiated separately with $20-\mathrm{keV} \mathrm{He}^{+}$or $10-\mathrm{keV} \mathrm{D}^{+}$ions to various doses

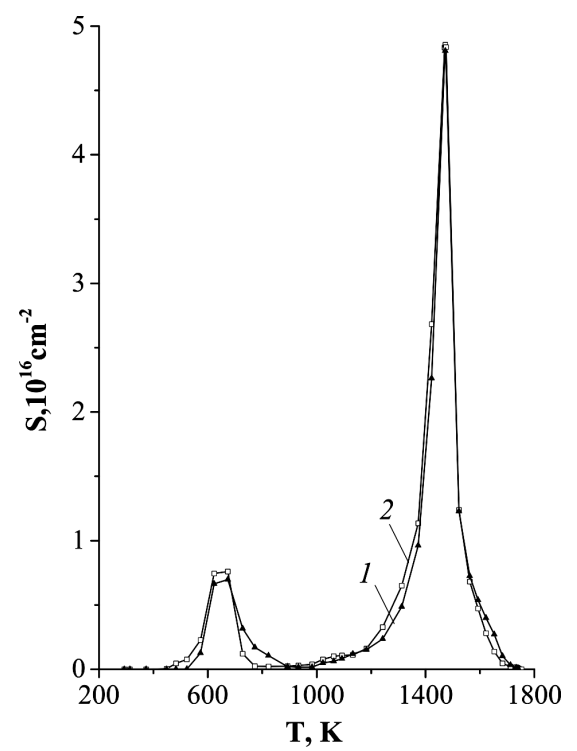

Fig. 6. Thermal desorption spectra of deuterium and helium from a tungsten coating of the $\mathrm{SS}+\mathrm{W}(\mu \mathrm{m})$ composite structure irradiated sequentially according to scenarios $\mathrm{He}^{+} \rightarrow \mathrm{D}^{+}$(1) and $\mathrm{D}^{+} \rightarrow \mathrm{He}^{+}(2)$. $\mathrm{D}^{+}$ions: $10 \mathrm{keV}, 3.0 \times 10^{17} \mathrm{~cm}^{-2} ; \mathrm{He}^{+}$ ions: $20 \mathrm{keV}, 2.0 \times 10^{17} \mathrm{~cm}^{-2} ; \alpha=0.8 \mathrm{~K} / \mathrm{s}$

maximum of the major peak of deuterium thermal desorption was found to be located at a temperature of $640 \mathrm{~K}$. For two highest exposure doses, the additional peak was also observed at a temperature close to $1400 \mathrm{~K}$.
From Fig. 4 (curves 1 to 4 ), one can see that the temperature interval of helium release equals $\Delta T \approx$ $900 \div 1800 \mathrm{~K}$. Helium is mainly released in the peak with $T_{\max } \approx \approx 1500 \mathrm{~K}$. But if $\Phi_{\mathrm{He}^{+}} \geq 4.7 \times 10^{17} \mathrm{~cm}^{-2}$ (curves 5 to 7 ), the thermal desorption spectrum of helium also contains a low-temperature interval $\Delta T \approx 350 \div 900 \mathrm{~K}$, which is superimposed on the interval with the $\mathrm{D}_{2}$ release.

The regularities of the helium and deuterium accumulations in the tungsten coatings of composite structures during the process of ion bombardment of the specimen are studied by analyzing the dependences of the concentration $C$ of the implanted gas and its capture coefficient $\eta$ on the dose $\Phi$ of irradiation with this gas. The values of the parameters $C$ and $\eta$ for He and D particles obtained for various doses $\Phi$ at separate irradiation doses are presented in Table. The dependences of $C$ and $\eta$ on $\Phi$ are depicted in Fig. 5 for implanted helium (curves 1 and 2 , respectively) and deuterium (curves $1^{\prime}$ and $2^{\prime}$, respectively).

From Fig. 5 and the data in Table, one can see that the values of the parameters $C$ and $\eta$ for implanted helium are much larger than those for implanted deuterium provided the same irradiation doses. An increase of the irradiation dose results in an increase of the $C$ values and a decrease of the $\eta$ ones for both types of ions. The dependence $C_{\mathrm{He}}\left(\Phi_{\mathrm{He}^{+}}\right)$tends to the saturation at the doses $\Phi_{\mathrm{He}^{+}} \geq 1.5 \times 10^{18} \mathrm{~cm}^{-2}$, which is associated with a larger amount of implanted and released $\mathrm{He}$ from the specimen during the ion bombardment. According to the results of works [34-36], if the tungsten foil is irradiated with medium-energy $\mathrm{He}^{+}$and $\mathrm{D}^{+}$ions, the exposure doses at which the saturation state is reached do not exceed, as a rule, $(0.4 \div 1.5) \times 10^{18} \mathrm{~cm}^{-2}$ for $\mathrm{He}^{+}$ions $[34,35]$ and $1.5 \times 10^{19} \mathrm{~cm}^{-2}$ for $\mathrm{D}^{+}$ ones [36].

The main specific feature of the metal saturation state consists in that the processes of formation and growth of gas bubbles in the gas-saturated layer undergo acceleration, when approaching this state, and, according to the results of work [35], an intense change of the metal surface layer begins as a result of the blistering. In this work, owing to the fine-grained structure of a W coating, the migration of helium is possible from gas bubbles to the surface along the grain boundaries. The formation of blisters is hardly probable at that.

ISSN 2071-0194. Ukr. J. Phys. 2020. Vol. 65, No. 1 


\subsection{Sequential irradiation of tungsten coatings with deuterium and helium ions}

Figure 6 illustrates the thermal desorption spectra of deuterium and helium from the tungsten coating of a composite structure sequentially irradiated with $\mathrm{D}^{+}\left(\Phi=3.0 \times 10^{17} \mathrm{~cm}^{-2}\right)$ and $\mathrm{He}^{+}(\Phi=2.0 \times$ $\times 10^{17} \mathrm{~cm}^{-2}$ ) ions following the $\mathrm{He}^{+} \rightarrow \mathrm{D}^{+}$(curve 1) and $\mathrm{D}^{+} \rightarrow \mathrm{He}^{+}$(curve 2) scenarios. For other doses of sequential irradiation with the ions concerned, the characters of the thermal desorption spectra of deuterium and helium were the same. The doses of $\mathrm{D}^{+}$ and $\mathrm{He}^{+}$ions used at the sequential irradiation are indicated in Table.

When comparing Figs. 3, 4, and 6, it becomes evident that the thermal desorption spectra of deuterium and helium, whose ions were sequentially implanted in different orders to the irradiation doses $\Phi_{\mathrm{D}^{+}} \leq 4.6 \times 10^{17} \mathrm{~cm}^{-2}$ and $\Phi_{\mathrm{He}^{+}} \leq 4.0 \times 10^{17} \mathrm{~cm}^{-2}$, are superpositions of the thermal desorption spectra of $\mathrm{D}^{+}$and $\mathrm{He}^{+}$implanted to the same doses, but separately. The temperature intervals $\Delta T$ of the deuterium and helium release remained the same. The temperatures $T_{\max }$ of their thermal desorption peaks have the same values for both separate and sequential implantations of $\mathrm{D}^{+}$and $\mathrm{He}^{+}$ions (see Table).

In Fig. 7, the dependences of the concentration $C_{\mathrm{D}}$ (curve 1 ) and the capture coefficient $\eta_{\mathrm{D}}$ (curve 2) for deuterium in the tungsten coatings of composite structures on the irradiation dose $\Phi_{\mathrm{D}^{+}}$with $\mathrm{D}^{+}$ions obtained in various irradiation scenarios are shown: for the separate irradiation with only $\mathrm{D}^{+}$ions (symbols $\bullet$ and $\boldsymbol{\Delta}$ ), for the sequential $\mathrm{He}^{+} \rightarrow \mathrm{D}^{+}$irradiation (symbols $\circ$ and $\triangle$ ), and for the sequential $\mathrm{D}^{+} \rightarrow \mathrm{He}^{+}$irradiation (symbols $\times$and $\star$ ). Analogous dependences for the concentration $C_{\mathrm{He}}$ (curve 1) and the capture coefficient $\eta_{\mathrm{He}}$ (curve 2) of helium on the irradiation dose $\Phi_{\mathrm{He}^{+}}$with $\mathrm{He}^{+}$ions obtained in various irradiation scenarios are shown in Fig. 8: for the separate irradiation with only $\mathrm{He}^{+}$ions (symbols - and $\boldsymbol{\Delta}$ ), for the sequential $\mathrm{He}^{+} \rightarrow \mathrm{D}^{+}$irradiation (symbols $\circ$ and $\triangle$ ), and for the sequential $\mathrm{D}^{+} \rightarrow \mathrm{He}^{+}$ irradiation (symbols $\times$ and $\star$ ). Figures 7 and 8 testify that, in various irradiation scenarios with $\mathrm{He}^{+}$ and $\mathrm{D}^{+}$ions, the values of the parameters $C_{\mathrm{He}}$ and $\eta_{\mathrm{He}}$ for implanted helium are much larger than their counterparts $C_{\mathrm{D}}$ and $\eta_{\mathrm{D}}$ for implanted deuterium.

Figure 9 demonstrates the concentration-versusdose dependences $C_{\mathrm{D}}\left(\Phi_{\mathrm{He}^{+}}\right)$(curve 1) and

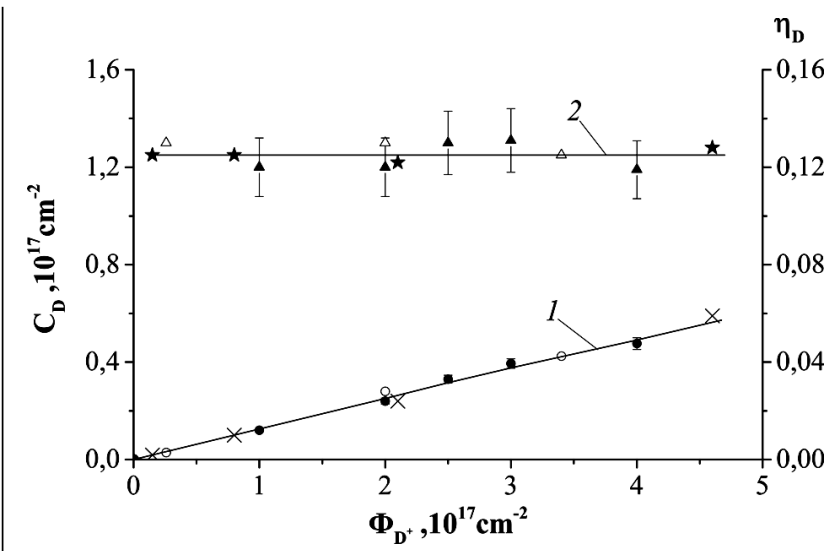

Fig. 7. Dependences of the concentration $C_{\mathrm{D}}(1)$ and the capture coefficient $\eta_{\mathrm{D}}$ (2) of deuterium in a tungsten coating of the $\mathrm{SS}+\mathrm{W}(\mu \mathrm{m})$ composite structure on the irradiation dose with only $\mathrm{D}^{+}$ions $(\bullet, \boldsymbol{\Delta}), \mathrm{He}^{+}$and $\mathrm{D}^{+}$ions in the sequence $\mathrm{He}^{+} \rightarrow \mathrm{D}^{+}(\circ, \triangle)$, and $\mathrm{D}^{+}$and $\mathrm{He}^{+}$ions in the sequence $\mathrm{D}^{+} \rightarrow \mathrm{He}^{+}(\times, \star) . \mathrm{He}^{+}$ions: $20 \mathrm{keV}, 2.0 \times 10^{17} \mathrm{~cm}^{-2} ; \mathrm{D}^{+}$ ions: $10 \mathrm{keV}$

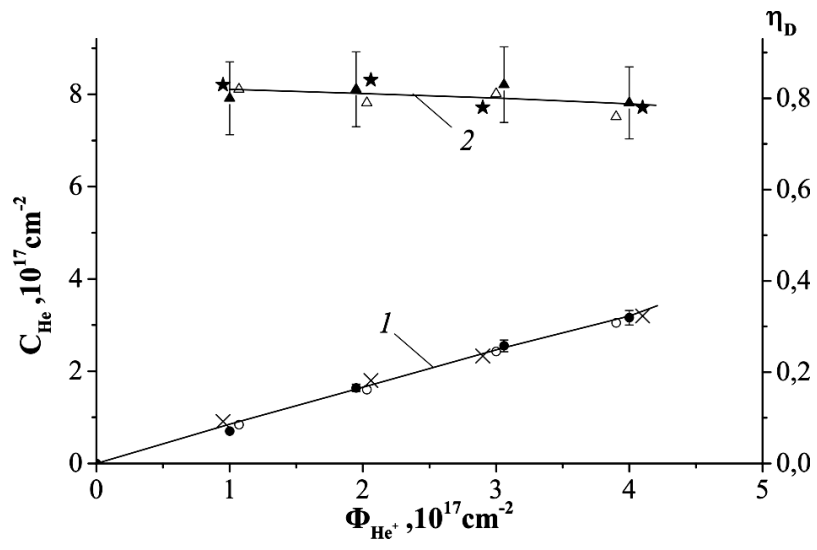

Fig. 8. Dependences of the concentration $C_{\mathrm{He}}$ (1) and the capture coefficient $\eta_{\mathrm{He}}$ (2) of helium in a tungsten coating of the $\mathrm{SS}+\mathrm{W}(\mu \mathrm{m})$ composite structure on the irradiation dose with only $\mathrm{He}^{+}$ions $(\bullet, \mathbf{\Delta}), \mathrm{He}^{+}$and $\mathrm{D}^{+}$ions in the sequence $\mathrm{He}^{+} \rightarrow \mathrm{D}^{+}(\mathrm{o}, \triangle)$, and $\mathrm{D}^{+}$and $\mathrm{He}^{+}$ions in the sequence $\mathrm{D}^{+} \rightarrow \mathrm{He}^{+}(\times, \star) . \mathrm{D}^{+}$ions: $10 \mathrm{keV}, 2.0 \times 10^{17} \mathrm{~cm}^{-2} ; \mathrm{He}^{+}$ ions: $10 \mathrm{keV}$

$C_{\mathrm{He}}\left(\Phi_{\mathrm{D}^{+}}\right)$(curve $1^{\prime}$ ) and the capture coefficientversus-dose dependences $\eta_{\mathrm{D}}\left(\Phi_{\mathrm{He}^{+}}\right)$(curve 2) and $\eta_{\mathrm{He}}\left(\Phi_{\mathrm{D}^{+}}\right)$(curve $2^{\prime}$ ) for deuterium (curves 1 and 2) and helium (curves $1^{\prime}$ and $2^{\prime}$ ) in the tungsten coatings of composite structures irradiated according to various scenarios: for the separate irradiation with only $\mathrm{D}^{+}$or $\mathrm{He}^{+}$ions (symbols $\bullet$ and $\boldsymbol{\Delta}$ ), for the sequential $\mathrm{He}^{+} \rightarrow \mathrm{D}^{+}$irradiation (symbols $\circ$ and 


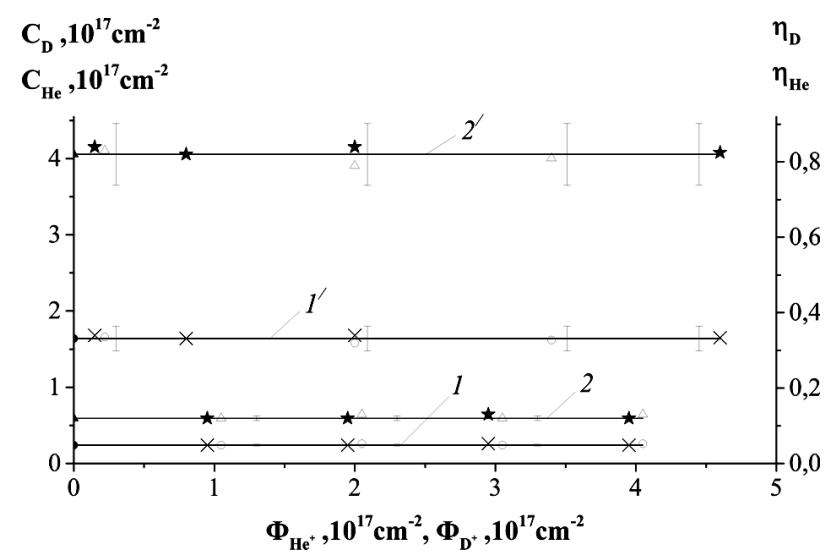

Fig. 9. Dependences $C_{\mathrm{D}}\left(\Phi_{\mathrm{He}^{+}}\right)(1), C_{\mathrm{He}}\left(\Phi_{\mathrm{D}^{+}}\right)\left(1^{\prime}\right)$, $\eta_{\mathrm{D}}\left(\Phi_{\mathrm{He}^{+}}\right)$(2), and $\eta_{\mathrm{He}}\left(\Phi_{\mathrm{D}^{+}}\right)\left(2^{\prime}\right)$ for helium and deuterium in a tungsten coating of the $\mathrm{SS}+\mathrm{W}(\mu \mathrm{m})$ composite structure irradiated with only $\mathrm{D}^{+}$or $\mathrm{He}^{+}$ions $(\bullet, \mathbf{\Delta})$, $\mathrm{He}^{+}$and $\mathrm{D}^{+}$ions in the sequence $\mathrm{He}^{+} \rightarrow \mathrm{D}^{+}(\circ, \triangle)$, and $\mathrm{D}^{+}$and $\mathrm{He}^{+}$ions in the sequence $\mathrm{D}^{+} \rightarrow \mathrm{He}^{+}(\times, \star)$. Curves 1 and 2 : $\Phi_{\mathrm{D}^{+}}=2.0 \times 10^{17} \mathrm{~cm}^{-2}$; curves $1^{\prime}$ and $\mathscr{2}^{\prime}$ : $\Phi_{\mathrm{He}^{+}}=2.0 \times 10^{17} \mathrm{~cm}^{-2}$

$\triangle$ ), and for the sequential $\mathrm{D}^{+} \rightarrow \mathrm{He}^{+}$irradiation (symbols $\times$ and $\star$ ). From the analysis of the results obtained, it follows that the previous and next implantations of helium to various doses within the interval $\Phi_{\mathrm{He}^{+}} \leq 4.0 \times 10^{17} \mathrm{~cm}^{-2}$ do not change the values of the parameters $C_{\mathrm{D}}$ and $\eta_{\mathrm{D}}$ for deuterium [see the dependences $C_{\mathrm{D}}\left(\Phi_{\mathrm{He}^{+}}\right)$(curve 1) and $\eta_{\mathrm{D}}\left(\Phi_{\mathrm{He}^{+}}\right)$(curve 2) in Fig. 9]. Furthermore, the previous and next implantations of deuterium to various doses in the interval $\Phi_{\mathrm{D}^{+}} \leq 4.6 \times 10^{17} \mathrm{~cm}^{-2}$ also do not change the values of the helium parameters $C_{\mathrm{He}}$ and $\eta_{\mathrm{He}}$ [see the dependences $C_{\mathrm{He}}\left(\Phi_{\mathrm{D}^{+}}\right)$(curve $1^{\prime}$ ) and $\eta_{\mathrm{He}}\left(\Phi_{\mathrm{D}^{+}}\right)$(curve $\left.2^{\prime}\right)$ in Fig. 9].

In the works performed by other authors for massive $\mathrm{W}$ foils $[13,14,16]$, the influence of the previous implantation of $\mathrm{He}^{+}$ions on the capture of deuterium implanted at the next stage in the framework of the $\mathrm{He}^{+} \rightarrow \mathrm{D}^{+}$scenario was demonstrated. If $\mathrm{D}^{+}$ions with energies of $1-4 \mathrm{keV}$ were implanted to the doses $\Phi_{\mathrm{D}^{+}}=(2 \div 3) \times 10^{17} \mathrm{~cm}^{-2}$ after the preliminary irradiation with $(8 \div 10)-\mathrm{keV} \mathrm{He}^{+}$ions to $0.3 \times 10^{17} \mathrm{~cm}^{-2} \leq \Phi_{\mathrm{He}^{+}} \leq 1.0 \times 10^{17} \mathrm{~cm}^{-2}$, the former did not change their accumulation [13]. But this parameter became 3 times as large, when the dose of $\mathrm{He}^{+}$ions reached $\Phi_{\mathrm{He}^{+}}=2.0 \times 10^{17} \mathrm{~cm}^{-2}[14]$. The cited authors associated those results with the capture of $\mathrm{D}$ particles by radiation-induced defects in the matrix in the former case [13] and with the influence of a high stress field emerging around separate helium bubbles in the latter one [14]. According to work [16], the further growth of the $\mathrm{He}^{+}$-ion $(3 \mathrm{keV})$ dose to $\Phi_{\mathrm{He}^{+}}=1.0 \times 10^{19} \mathrm{~cm}^{-2}$ resulted in a decrease of the deuterium capture due to the influence of a formed network of helium bubbles on the deuterium accumulation. A reduction in the deuterium capture was also observed by the authors of work [16] at the sequential $\mathrm{D}^{+} \rightarrow \mathrm{He}^{+}$implantation to the doses $\Phi_{\mathrm{D}^{+}}=1.0 \times 10^{17} \mathrm{~cm}^{-2}$ and $\Phi_{\mathrm{He}^{+}}=1.0 \times 10^{17} \mathrm{~cm}^{-2}$, which was induced by the radiation-accelerated diffusion of weakly trapped deuterium atoms to the specimen surface followed by their release into vacuum under the further irradiation with $\mathrm{He}^{+}$ions. Probably, the differences in the formation of helium bubbles in our studies (see below) and in works $[13,14,16]$ may explain the character of the deuterium accumulation at the sequential $\mathrm{He}^{+} \rightarrow \mathrm{D}^{+}$implantation into the tungsten coatings.

\subsection{Electron microscopy studies} of tungsten coatings in composite structures irradiated with deuterium and helium ions

Transmission electron microscopy (TEM) was used to study the structure of tungsten coatings in the initial specimens and in the specimens irradiated with $\mathrm{D}^{+}$ or $\mathrm{He}^{+}$ions. In the initial state, the $\mathrm{W}$ coatings had a polycrystalline bcc structure. In Fig. 10, the micrographs of tungsten coating structures are shown: $(a)$ in the initial state, $(b)$ after the irradiation with deuterium ions, and $(c)$ after the irradiation with helium ions.

From Fig. 10, $b$, one can see that the grains of the crystalline structure in a tungsten coating irradiated with $\mathrm{D}^{+}$ions to the dose $\Phi_{\mathrm{D}^{+}}=6 \times 10^{18} \mathrm{~cm}^{-2}$ contain a large number of black dots with the average diameter exceeding $5 \mathrm{~nm}$ and a concentration of $(3.2 \pm 0.3) \times 10^{12} \mathrm{~cm}^{-2}$. Seemingly, these are penetrating dislocation loops. The works of other authors $[8,36]$ report results concerning the formation of interstitial dislocation loops and dislocation networks at $T_{o}=300 \div 350 \mathrm{~K}$ in a single-crystalline $\mathrm{W}$ irradiated with $\mathrm{D}_{2}^{+}$ions with an energy of $10 \mathrm{keV}$ to the dose $\Phi_{\mathrm{D}^{+}}=2 \times 10^{18} \mathrm{~cm}^{-2}$ [36] and with $\mathrm{H}^{+}$ ions with an energy of $10 \mathrm{keV}$ to the dose $\Phi_{\mathrm{H}^{+}}=$ $=3 \times 10^{18} \mathrm{~cm}^{-2}$ [8]. The results were obtained by channeling the megaelectronvolt ${ }^{4} \mathrm{He}^{+}$ions along 

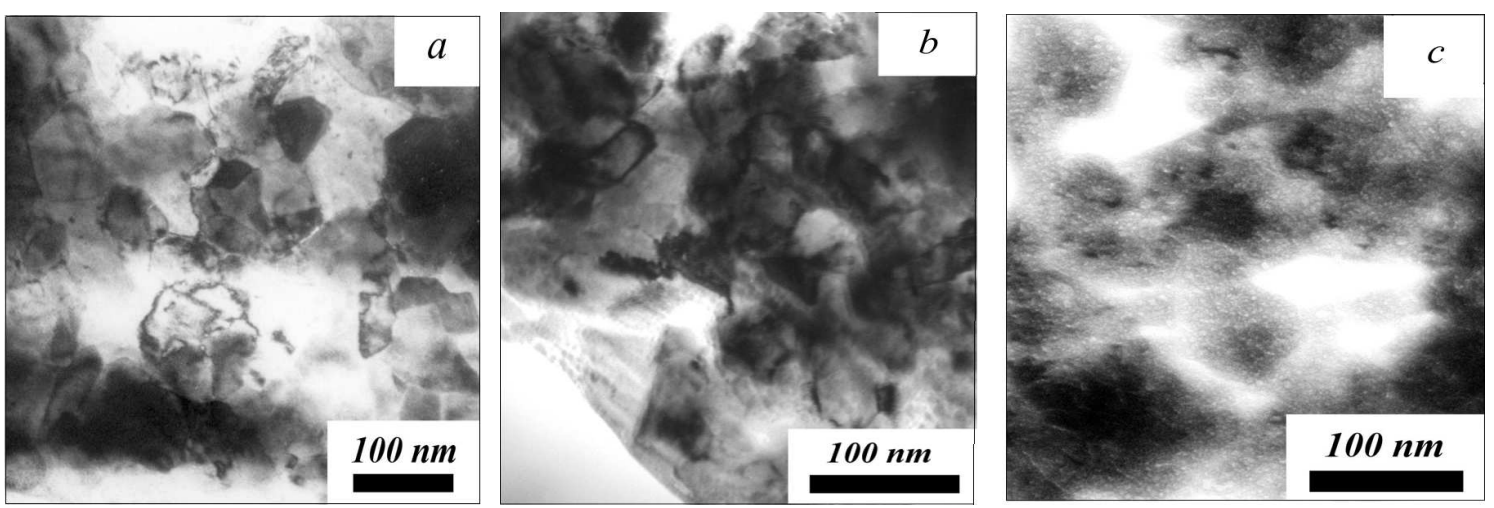

Fig. 10. Electron microscopy images of a tungsten coating of the $\mathrm{SS}+\mathrm{W}(\mu \mathrm{m})$ composite structure $(a)$ in the initial state, $(b)$ after irradiation with $10-\mathrm{keV} \mathrm{D} \mathrm{D}^{+}$ions to the dose $\Phi_{\mathrm{D}^{+}}=6 \times 10^{18} \mathrm{~cm}^{-2}$, and $(c)$ after irradiation with $20-\mathrm{keV} \mathrm{He}^{+}$ions to the dose $\Phi_{\mathrm{He}^{+}}=7 \times 10^{17} \mathrm{~cm}^{-2}$

$\langle 111\rangle \mathrm{W}$ accompanied by the detection of backscattered ${ }^{4} \mathrm{He}^{+}$ions and TEM studies.

According to the results of works $[9,10]$, where TEM studies of metallurgical grade W (99.95\%) and superpurity W $(99.995 \%)$ were carried out, the irradiation with $\mathrm{He}^{+}$ions $\left(8 \mathrm{keV}, 1.0 \times 10^{14} \mathrm{~cm}^{-2} \leq\right.$ $\left.\leq \Phi_{\mathrm{He}^{+}} \leq 6.5 \times 10^{15} \mathrm{~cm}^{-2}\right)$ at the temperature $T_{o}=293 \mathrm{~K}$ also results in the formation of penetrating dislocation loops. As the dose $\Phi$ increases, the average size of the loops grew to $5.0 \mathrm{~nm}$, and their concentration reached a value of $3.5 \times 10^{12} \mathrm{~cm}^{-2}$. Afterward, they were accumulated as entangled dislocations. We may assume that, in those studies, the formation of interstitial dislocation loops and dislocation networks in the tungsten coatings of composites irradiated with $\mathrm{He}^{+}$ions also took place.

In Fig. 10, $c$, the black dots are not visible because the electron focusing mode in the TEM experiment was selected to detect the formation of helium bubbles in the coating.

No formation of helium bubbles was observed in the tungsten coating after its irradiation with $\mathrm{He}^{+}$ions up to doses $\Phi_{\mathrm{He}^{+}} \leq 4 \times 10^{17} \mathrm{~cm}^{-2}$ at room temperature. Helium bubbles were detected after the irradiation with $\mathrm{He}^{+}$ions to doses $\Phi_{\mathrm{He}^{+}} \geq 7 \times 10^{17} \mathrm{~cm}^{-2}$. They had an average diameter of about $2.5 \mathrm{~nm}$ and a concentration of $(5.0 \pm 0.5) \times 10^{12} \mathrm{~cm}^{-2}$ at the dose $\Phi_{\mathrm{He}^{+}}=7 \times 10^{17} \mathrm{~cm}^{-2}$ (see Fig. 10,c). The formation of helium bubbles does not change the bcc structure of the crystal lattice in the $\mathrm{W}$ coating. According to the results of works $[9,10]$, helium bubbles were observed in the specimens of metallurgical grade W (99.95\%) and superpurity W (99.995\%) irradiated with $8-\mathrm{keV}$ $\mathrm{He}^{+}$ions to the doses $\Phi_{\mathrm{He}^{+}} \geq 2 \times 10^{17} \mathrm{~cm}^{-2}$ at room temperature. The average diameter of those bubbles was about $2.5 \mathrm{~nm}$, and their concentration was much higher than the concentration of dislocation loops $\left(3.5 \times 10^{12} \mathrm{~cm}^{-2}\right)$.

After the irradiation of the tungsten coating with $\mathrm{D}^{+}$ions to a maximum dose of $6 \times 10^{18} \mathrm{~cm}^{-2}$ at room temperature, no formation of deuterium bubbles with the average diameter exceeding $2.5 \mathrm{~nm}$ and no changes in the bcc structure were detected. According to the results of work [3], deuterium bubbles in tungsten are formed at the irradiation with $\mathrm{D}^{+}$ions to doses exceeding $1 \times 10^{19} \mathrm{~cm}^{-2}$. This is about two orders of magnitude higher than the corresponding irradiation dose with $\mathrm{He}^{+}$ions.

The method of reflection electron microscopy (REM) is applied to study the surface morphology of tungsten-coated composite systems. Initial specimens, specimens irradiated with $\mathrm{D}^{+}$or $\mathrm{H}^{+}$ions, and specimens - preliminary irradiated or not - annealed to $1800 \mathrm{~K}$ are studied. In the latter case, the specimens were annealed at a heating rate of $0.8 \mathrm{~K} / \mathrm{s}$. It is found that the surface morphology of the specimens irradiated at room temperature with $\mathrm{D}^{+}$ions to doses $\Phi_{\mathrm{D}^{+}} \leq 2.0 \times 10^{18} \mathrm{~cm}^{-2}$ or with $\mathrm{He}^{+}$to doses $\Phi_{\mathrm{He}^{+}} \leq 5.0 \times 10^{18} \mathrm{~cm}^{-2}$ is not changed. No formation of blisters was not observed on the surface of specimens irradiated with $\mathrm{D}^{+}$or $\mathrm{He}^{+}$ions and annealed to a temperature of $1800 \mathrm{~K}$. An insignificant worsening of the coating specularity (a higher roughness) was observed at $T>1600 \mathrm{~K}$. 
After the specimens were heated to $T=1800 \mathrm{~K}$, the growth of grains of the crystalline lattice of a $\mathrm{W}$ coating (recrystallization) is observed. According to the data of work [37], pure tungsten undergoes the recrystallization at $T>1700 \mathrm{~K}$, with the concentrations of dislocations and grain boundaries decreasing at that. The grain size increases by about an order of magnitude. In this work, the recrystallization was detected at temperatures above the temperatures of maximum helium $(T \gtrsim 1520 \mathrm{~K})$ and deuterium $(T \gtrsim 1400 \mathrm{~K})$ release into vacuum, and its effect on the thermal desorption spectra of indicated gases from tungsten coatings is insignificant.

\subsection{Radiation defects induced by implanted deuterium and helium ions in tungsten coatings of composite structures}

In the course of bombarding the tungsten coatings with $\mathrm{D}^{+}$or $\mathrm{He}^{+}$ions, there arise radiation defects of various types in them: defects in the material crystal lattice and impurities in the form of implanted ion beam particles. In order to determine the origin of the generated radiation defects, we, as was done earlier in works $[27,28,33,38,39]$, analyzed the capture, migration, and release of implanted deuterium and helium particles from the specimens into vacuum with the help of thermal desorption spectra. In particular, this method was used, when determining the activation energy of the thermal desorption $E_{a}$ in the main peaks of particle release spectra. Electron microscopy observations gave us information about structural defects (dislocations, defect accumulations, bubbles of implanted gases). The kit of applied methods allowed us

- to obtain a more detailed information on the formation and annealing of radiation defects, including their origin; the mechanisms of defect accumulation and transformation in the crystal lattice; the migration of gas particles to the specimen surface and their further desorption into vacuum;

- to describe the mechanisms governing the formation of penetrating dislocation loops; the accumulation of radiation-induced matrix defects and implanted particles from the bombarding beam, as well as their interaction that gives rise to the formation of gas-vacancy complexes;

- to propose mechanisms governing the annealing of radiation damages in the crystal lattice, namely, the dissociation of complexes and the migration of defects to sinks in the coating bulk, which results in the formation of gas bubbles, and to the coating surface, which results in the desorption of gases into vacuum.

If $\mathrm{D}^{+}\left(\Phi_{\mathrm{D}^{+}} \leq 4.6 \times 10^{17} \mathrm{~cm}^{-2}\right)$ and $\mathrm{He}^{+}\left(\Phi_{\mathrm{He}^{+}} \leq\right.$ $\left.\leq 4.0 \times 10^{17} \mathrm{~cm}^{-2}\right)$ ions are sequentially implanted into the tungsten coatings in different orders, (i) the helium (deuterium) accumulation depends on neither the previous nor next irradiation with deuterium (helium) ions, and (ii) the thermal desorption spectra of $\mathrm{D}_{2}$ and He particles are superpositions of the thermal desorption spectra of deuterium and helium implanted separately. In this case, the temperature intervals of the deuterium and helium releases into vacuum, as well as the temperatures $T_{\max }$ corresponding to the maxima of their thermal desorption peaks, remain the same. The intensities of the thermal desorption peaks of $\mathrm{D}_{2}$ and He into vacuum also do not depend on the scenario of the irradiation with $\mathrm{D}^{+}$and $\mathrm{He}^{+}$ions.

Proceeding from those facts, we assumed that the types of radiation-induced damages in the tungsten coatings with composite structure irradiated with $\mathrm{D}^{+}$and $\mathrm{He}^{+}$ions, both separately and sequentially, and the mechanisms of their annealing can be the same. We supposed that, in the tungsten coating irradiated at room temperature with $\mathrm{D}^{+}$and $\mathrm{He}^{+}$ ions, there arise radiation defects of the vacancy type. Those defects capture deuterium or helium into gas-vacancy complexes: $\mathrm{D}_{m} \mathrm{~V}_{n}$ or $\mathrm{He}_{m} \mathrm{~V}_{n}$. If the concentration of implanted gases increases, those complexes transform into gas bubbles (e.g., the formation of helium bubbles at irradiation doses $\Phi_{\mathrm{He}^{+}} \geq$ $\left.\geq 7 \times 10^{17} \mathrm{~cm}^{-2}\right)$. Furthermore, the irradiation with $\mathrm{D}^{+}$and $\mathrm{He}^{+}$ions brings about the appearance of interstitial atoms in the $\mathrm{W}$ lattice, and their radiationstimulated migration is observed with the formation of clusters and complexes of the penetrating dislocation loop type.

According to the results of calculations [40], the release of deuterium in the main peak $\left(T_{\max }=640 \mathrm{~K}\right)$ with the activation energy of thermal desorption $E_{a}=1.4 \mathrm{eV}$ may occur due to the dissociation of deuterium-vacancy complexes, the migration of deuterium atoms through the interstitial sites to the surface, and the subsequent desorption of $\mathrm{D}_{2}$ into vacuum. The high-temperature peak $\left(T_{\max } \approx 1400 \mathrm{~K}\right)$ of deuterium thermal desorption from the $\mathrm{W}$ coating, which is observed at irradiation doses $\Phi_{\mathrm{D}^{+}} \geq$ 
$\geq 8.0 \times 10^{17} \mathrm{~cm}^{-2}$, is most probably associated with the formation of deuterium bubbles at the heating and with the release of deuterium from them. At such $\Phi_{\mathrm{D}^{+}}$values, gas bubbles are formed in metals, as a rule, at $T>0.4 T_{\text {melt }}$ (for $\mathrm{W}, 0.4 T_{\text {melt }}=1470 \mathrm{~K}$ ).

The authors of works $[41,42]$ also showed that deuterium is mainly released in the peak with $T_{\max } \approx$ $\approx 630 \mathrm{~K}$, if it was implanted into $\mathrm{W}$ at room temperature to the doses $\Phi_{\mathrm{D}^{+}} \leq 1 \times 10^{17} \mathrm{~cm}^{-2}$. The cited authors connected the peak origin with the release of deuterium at the dissociation of deuterium-vacancy complexes $\mathrm{DV}_{n}$, where $n=4 \div 10$, the migration of deuterium atoms through the interstitial sites to the surface with the migration energy $E_{\mathrm{D}, i}^{m} \approx 0,39 \mathrm{eV}$, and the subsequent desorption of $\mathrm{D}_{2}$ into vacuum.

From work [43], it is known that, in tungsten irradiated with $8-\mathrm{keV} \mathrm{H}^{+}$ions to the dose $\Phi_{\mathrm{H}^{+}}=1 \times$ $\times 10^{18} \mathrm{~cm}^{-2}$, the formation of penetrating dislocation loops was observed at $T_{0}=473 \mathrm{~K}$, and the formation of hydrogen bubbles at $T_{0}=873 \mathrm{~K}$. In work [44], the release of deuterium was observed in the peak with $T_{\max } \approx 1400 \mathrm{~K}$ from tungsten irradiated with 3 -keV $\mathrm{D}^{+}$ions to the dose $\Phi_{\mathrm{D}^{+}}=4 \times 10^{18} \mathrm{~cm}^{-2}$. The cited authors explained it by the movement of dislocations owing to the recrystallization of tungsten at its heating. According to the results of work [37], the recrystallization in tungsten occurs at $T>1700 \mathrm{~K}$. In our work, this process is relevant for the tails of the thermal desorption spectrum and, therefore, has little effect on the process of deuterium release into vacuum.

The peak with $T_{\max } \approx 1500 \mathrm{~K}$ was the main one in the spectrum of helium thermal desorption at $1.0 \times 10^{17} \mathrm{~cm}^{-2} \leq \Phi_{\mathrm{He}^{+}} \leq 4.0 \times 10^{17} \mathrm{~cm}^{-2}$. It was also observed at higher irradiation doses $\Phi_{\mathrm{He}^{+}} \geq$ $\geq 4.7 \times 10^{17} \mathrm{~cm}^{-2}$, although the corresponding fraction of captured helium did not exceed $30 \%$. According to calculations [40], the peak has the activation energy of the helium thermal desorption $E_{a} \approx 4.2 \mathrm{eV}$. According to the results of work [45], the diffusion of helium in the $\mathrm{W}$ crystal lattice takes place owing to the dissociation of the helium-vacancy complex of the $\mathrm{HeV}$ type, the migration of helium atoms through the interstitial sites to the surface (the migration energy $E_{\mathrm{He}, i}^{m} \approx 0.28 \mathrm{eV}$ ), and the subsequent desorption of He into vacuum. This process is characterized by the activation energy $E_{\mathrm{HeV}}^{\text {diss }} \approx 4.42 \mathrm{eV}$, which is close to the $E_{a}$ value. Therefore, the assumption can be made that the peak of the He thermal desorption corresponds to the migration of $\mathrm{He}$ through the interstitial sites to the surface, which occurs after the dissociation of helium-vacancy complexes $\mathrm{HeV}$. In work [46], it was shown that, in the case of tungsten irradiated with $60-\mathrm{keV} \mathrm{He}^{+}$ions to the dose $\Phi_{\mathrm{He}^{+}}=2 \times 10^{13} \mathrm{~cm}^{-2}$, helium is released at $T \approx 1500 \mathrm{~K}$, which the cited authors also explained by the release from $\mathrm{HeV}$ monovacancies.

In this work, we did not reveal the formation of helium bubbles in tungsten coatings irradiated with $\mathrm{He}^{+}$ions at room temperature to doses $\Phi_{\mathrm{He}^{+}} \leq 4.0 \times$ $\times 10^{17} \mathrm{~cm}^{-2}$. On the contrary, the irradiation of tungsten coatings at room temperature with $\mathrm{He}^{+}$ions to doses $\Phi_{\mathrm{He}^{+}} \geq 7.0 \times 10^{17} \mathrm{~cm}^{-2}$ resulted in the formation of helium bubbles. The doses of irradiation with $\mathrm{He}^{+}$ions applied in this work are in agreement with the doses $\Phi_{\mathrm{He}^{+}}=(2.0 \div 8.0) \times 10^{17} \mathrm{~cm}^{-2}$ applied in work [9], where the formation of helium bubbles in $\mathrm{W}$ foils also took place after the irradiation with $8-\mathrm{keV}$ helium ions at the temperature $T_{0}=293 \mathrm{~K}$. The thermal desorption of helium from a tungsten coating into vacuum at $T \leq 1400 \mathrm{~K}\left(\right.$ at $\Phi_{\mathrm{He}^{+}} \geq 4.7 \times 10^{17} \mathrm{~cm}^{-2}$ ) is associated with its release from available defects in the tungsten coating structure after the formation of helium bubbles.

Further studies of the formation and annealing of radiation-induced defects in the matrix and the accumulation of particles from the bombardment beam in the matrix at the doses of the sequential irradiation of a tungsten coating that are higher than those used in this work are a matter of our future interest.

\section{Conclusions}

The following processes are studied for the tungsten coatings of $\mathrm{SS}+\mathrm{W}(\mu \mathrm{m})$ composite structures irradiated with medium-energy $\mathrm{D}^{+}$and $\mathrm{He}^{+}$ions and afterward subjected to the heating: (i) the accumulation of deuterium and helium particles; (ii) the formation and annealing of intrinsic and radiationinduced defects in the matrix; (iii) the thermal desorption of ion-implanted deuterium and helium from the specimens into vacuum; and (iv) changes in the morphology of the specimen surface. The irradiation with $\mathrm{D}^{+}$and $\mathrm{He}^{+}$ions was performed at room temperature to the doses $\Phi_{\mathrm{D}^{+}} \leq 4.0 \times 10^{17} \mathrm{~cm}^{-2}$ and $\Phi_{\mathrm{He}^{+}} \leq 4.7 \times 10^{17} \mathrm{~cm}^{-2}$, respectively, when applying the sequential $\left(\mathrm{He}^{+} \rightarrow \mathrm{D}^{+}\right.$or $\left.\mathrm{D}^{+} \rightarrow \mathrm{He}^{+}\right)$irradiation scenarios, and to the doses $0.2 \times 10^{17} \mathrm{~cm}^{-2} \leq \Phi_{\mathrm{D}^{+}} \leq$ $\leq 16.5 \times 10^{17} \mathrm{~cm}^{-2}$ and $1.0 \times 10^{17} \mathrm{~cm}^{-2} \leq \Phi_{\mathrm{He}^{+}} \leq$ 
$\leq 35.5 \times 10^{17} \mathrm{~cm}^{-2}$, respectively, if the bombardment was carried out with either $\mathrm{D}^{+}$or $\mathrm{He}^{+}$ions separately.

General regularities are found for the separate and sequential implantations of $\mathrm{D}^{+}$and $\mathrm{He}^{+}$ions into tungsten coatings. In particular, deuterium is accumulated in the tungsten coating to lower concentrations in comparison with helium, and its capture coefficient is approximately an order of magnitude lower. The main release of deuterium from the specimens into vacuum occurs at lower temperatures in comparison with that of helium.

At the sequential implantations of $\mathrm{D}^{+}$and $\mathrm{He}^{+}$ ions, the temperature intervals of the deuterium and helium releases and the temperatures of the peaks in their thermal desorption spectra have the values identical to those obtained at separate implantations. The accumulation of deuterium (helium) does not depend on the previous irradiation with $\mathrm{He}^{+}\left(\mathrm{D}^{+}\right)$ions.

The following types of radiation-induced damages are assumed to be formed in the tungsten coating bulk: defects of the vacancy type, penetrating dislocation loops, and gas-vacancy complexes $\mathrm{He}_{m} \mathrm{~V}_{n}$ and $\mathrm{D}_{m} \mathrm{~V}_{n}$. Possible mechanisms of deuterium and helium accumulation and their thermally induced release from a tungsten coating are considered. Probably, implanted deuterium is captured by defects of the vacancy type. As the temperature of the postimplantation heating grows, the prevailing release of deuterium is associated with the dissociation of deuterium-vacancy complexes, the migration of deuterium particles to the surface, and the deuterium desorption into vacuum. For the irradiation doses $\Phi_{\mathrm{D}^{+}} \geq 8.0 \times 10^{17} \mathrm{~cm}^{-2}$, the formation of deuterium bubbles at the heating and the deuterium release from them are possible. The accumulation of helium in a tungsten coating is probably takes place by its capture into helium-vacancy complexes with the subsequent formation of helium bubbles. The thermal desorption of helium may be associated with its release from the helium-vacancy complexes at their dissociation, as well as from available defects in the tungsten coating structure after the formation of helium bubbles.

1. R.A. Causey. Hydrogen isotope retention and recycling in fusion reactor plasma-facing components. J. Nucl. Mater. 300, 91 (2002).

2. C.H. Skinner, A.A. Haasz, V.Kh. Alimov, N. Bekris, R.A. Causey, R.E.H. Clark, J.P. Coad, J.W. Davis, R.P. Doerner, M. Mayer, A. Pisarev. Recent advances on hydrogen retention in ITER's plasma-facing materials: beryllium, carbon, and tungsten. Fusion Sci. Technol. 54, 891 (2008).

3. F. Liu, Y. Zhang, W. Han, Zh. Shen, J. Yu, G. Lu, K. Zhu. Investigation of hydrogen behavior in tungsten exposed to high energy hydrogen plasma. Nucl. Instrum. Meth. B 307, 320 (2013).

4. W. Hu, F. Luo, Z. Shen, L. Guo, Zh. Zheng, Y. Wen, Y. Ren. Hydrogen bubble formation and evolution in tungsten under different hydrogen irradiation conditions. $\mathrm{Fu}$ sion Eng. Des. 90, 23 (2015).

5. Y. Furuta, I. Takagi, Sh. Kawamura, K. Yamamichi, M. Akiyoshi, T. Sasaki, T. Kobayashi. In situ deuterium observation in deuterium-implanted tungsten. Nucl. Instrum. Meth. B 315, 121 (2013).

6. T. Ahlgren, K. Heinola, K. Vortler, J. Keinonen. Simulation of irradiation induced deuterium trapping in tungsten. J. Nucl. Mater. 427, 152 (2012).

7. A. Debelle, P.-E. Lhuillier, M.-F. Barthe, T. Sauvage, P. Desgardin. Helium desorption in ${ }^{3} \mathrm{He}$ implanted tungsten at low fluence and low energy. Nucl. Instrum. Meth. B 268, 223 (2010).

8. I.I. Arkhipov, S.L. Kanashenko, V.M. Sharapov, R.Kh. Zalavutdinov, A.E. Gorodetsky. Deuterium trapping in iondamaged tungsten single crystal. J. Nucl. Mater. 363365, 1168 (2007).

9. H. Iwakiri, K. Yasunaga, K. Morishita, N. Yoshida. Microstructure evolution in tungsten during low-energy helium ion irradiation. J. Nucl. Mater. 283-287, 1134 (2000).

10. Y. Watanabe, H. Iwakiri, N. Yoshida, K. Morishita, A. Kohyama. Formation of interstitial loops in tungsten under helium ion irradiation: Rate theory modeling and experiment. Nucl. Instrum. Meth. B 255, 32 (2007).

11. P.E. Lhuillier, A. Debelle, T. Belhabib, A.L. Thomann, P. Desgardin, T. Sauvage, M. F. Barthe, P. Brault, Y. Tessier. Helium desorption in ${ }^{3} \mathrm{He}$ implanted tungsten at low energy. J. Nucl. Mater. 417, 504 (2011).

12. O. El-Atwani, K. Hattar, J.A. Hinks, G. Greaves, S.S. Harilal, A. Hassanein. Helium bubble formation in ultrafine and nanocrystalline tungsten under different extreme conditions. J. Nucl. Mater. 458, 216 (2015).

13. S. Nagata, K. Takahiro. Effect of helium irradiation on trapping and thermal release of deuterium implanted in tungsten. J. Nucl. Mater. 290-293, 135 (2001).

14. H. Iwakiri, K. Morishita, N. Yoshida. Effects of helium bombardment on the deuterium behavior in tungsten. J. Nucl. Mater. 307-311, 135 (2002).

15. S. Nagata, S. Yamamoto, K. Tokunaga, B. Tuschiya, K. Toh, T. Shikama. Hydrogen up-take in noble gas implanted W. Nucl. Instrum. Meth. B 242, 535 (2006).

16. Y. Sakoi, M. Miyamoto, K. Ono, M. Sakamoto. Helium irradiation effects on deuterium retention in tungsten. J. Nucl. Mater. 442, S715 (2013). 
17. F. Liu, Sh. Peng, H. Ren, Zh. Long, W. Han, J. Yu, Zh. Chen, K. Zhu. Effect of the displacement damage from argon ion irradiation on the synergistic effect of heliumhydrogen in tungsten. Fusion Eng. Des. 89, 2516 (2014).

18. Y. Nobuta, Y. Hatano, M. Matsuyama, S. Abe, Y. Yamauchi, T. Hino. Helium irradiation effects on tritium retention and long-term tritium release properties in polycrystalline tungsten. J. Nucl. Mater. 463, 993 (2015).

19. C. García-Rosales, P. Franzen, H. Plank, J. Roth, E. Gauthier. Re-emission and thermal desorption of deuterium from plasma sprayed tungsten coatings for application in ASDEX-upgrade. J. Nucl. Mater. 233-237, 803 (1996).

20. I. Bizyukov, K. Krieger, N. Azarenkov, S. Levchuk, Ch. Linsmeier. Formation of D inventories and structural modifications by deuterium bombardment of tungsten thin films. J. Nucl. Mater. 337-339, 965 (2005).

21. J. Matějíček, P. Chráska, J. Linke. Thermal spray coatings for fusion applications. Review. J. Thermal Spray Technol. 16, 64 (2007).

22. A.V. Golubeva, V.A. Kurnaev, M. Mayer, I. Rot. Capture of deuterium into plasma-sputtered tungsten. Vopr. At. Nauki Tekhn. Ser. Termoyad. Sintez No. 2, 18 (2007) (in Russian).

23. G. De Temmerman, R. P. Doerner. Deuterium retention and release in tungsten co-deposited layers. J. Nucl. Mater. 389, 479 (2009).

24. Y. Zhang, W. Wang, H. Ren, W. Han, F. Liu, J. Yu, Sh. Peng, K. Zhu. Hydrogen irradiation effect of $\mathrm{W}$ thin films prepared by magnetron sputtering deposition. Nucl. Instrum. Meth. B 307, 357 (2013).

25. K. Katayama, K. Uehara, H. Date, S. Fukada, H. Watanabe. Temperature dependence of deuterium retention in tungsten deposits by deuterium ion irradiation. J. Nucl. Mater. 463, 1033 (2015).

26. V.Kh. Alimov, J. Roth, W. M. Shu, D. A. Komarov, K. Isobe, T. Yamanishi. Deuterium trapping in tungsten deposition layers formed by deuterium plasma sputtering. J. Nucl. Mater. 399, 225 (2010).

27. V.V. Bobkov, A.V. Onishchenko, O.V. Sobol, R.I. Starovoitov, Yu.I. Kovtunenko, Yu.E. Logachev, L.P. Tishchenko. Ion-implanted deuterium accumulation in a deposited tungsten coating. J. Surf. Invest. X-ray 4, 852 (2010).

28. V.V. Bobkov, L.P. Tishchenko, A.V. Onishchenko, E.N. Zubarev, R.I. Starovoitov, Yu.I. Kovtunenko, Yu.E. Logachev, L.A. Gamayunova. Implantation of helium and deuterium ions into tungsten-coated composite structures. J. Surf. Invest. X-ray 5, 806 (2011).

29. V.V. Bobkov, L.P. Tishchenko, T.I. Peregon, Yu.I. Kovtunenko. Hydrogen isotope retention and lattice damage in the constructive materials irradiated with $\mathrm{H}^{+} / \mathrm{D}^{+}$ions. East Eur. J. Phys. 3, No. 3, 47 (2016).

30. N.A. Azarenkov, V.V. Bobkov, L.P. Tishchenko, R.I. Starovoitov, Yu.I. Kovtunenko, Yu.E. Logachev, L.A. Gamayunova. Sequential implantations of deuterium and helium ions into tungsten-coated composite structures. Probl. Atom. Sci. Technol. Ser. Plasma Physics 3, No. 6, 73 (2016).
31. J.P. Biersack, J.F. Ziegler. The stopping and range of ions in solids. In: Ion Implantation Techniques (Springer, 1982), p. 122 .

32. B.M. Smirnov. Atomic Collisions and Elementary Processes in Plasma (Atomizdat, 1968) (in Russian).

33. L.P. Tishchenko, T.I. Peregon, Yu.I. Kovtunenko, V.V. Bobkov, A.V. Onishchenko, R.I. Starovoitov. Investigation of the capture processes and gas evolution of ionimplanted deuterium from tungsten films. Izv. Ross. Akad. Nauk. Ser. Fiz. 70, 1197 (2006) (in Russian).

34. T. Hino, Y. Yamauchi, Y. Hirohata. Helium retention of plasma facing materials. J. Nucl. Mater. 266-269, 538 (1999).

35. Zh. Fu, N. Yoshida, H. Iwakiri, Z. Xu. Thermal desorption and surface modification of $\mathrm{He}^{+}$implanted into tungsten. J. Nucl. Mater. 329-333, 692 (2004).

36. S. Nagata, K. Takahiro, S. Horiike, S. Yamaguchi. Retention and release of deuterium implanted in $\mathrm{W}$ and Mo. J. Nucl. Mater. 266-269, 1151 (1999).

37. A. Manhard, K. Schmid, M. Balden, W. Jacob. Influence of the microstructure on the deuterium retention in tungsten. J. Nucl. Mater. 415, S632 (2011).

38. V.V. Bobkov, R.I. Starovoitov, L.P. Tishchenko, E.N. Zubarev, Yu.I. Kovtunenko, Yu.E. Logachev. The influence of deuterium and helium implanted ions on the structure of condensed tungsten coating. In: Proceedings of the 20th International Conference on Ion-Surface Interactions, Zvenigorod, Russia, August 25-29 (2011), Vol. 2, p. 61 .

39. V.V. Bobkov, R.I. Starovoitov, L.P. Tishchenko, Yu.I. Kovtunenko, L.A. Gamayunova. Deuterium-ion implantation into composite structures with tungsten coatings. J. Surf. Invest. X-ray 8, 853 (2014).

40. G. Carter. Thermal resolution of desorption energy spectra. Vacuum 12, 245 (1962).

41. V.S. Efimov, Yu.M. Gasparyan, A.A. Pisarev. Investigation of a fine structure of deuterium thermal desorption spectra from tungsten. In: Proceedings of the 20th International Conference on Ion-Surface Interactions, Zvenigorod, Russia, August 25-29 (2001), Vol. 1, p. 306.

42. H. Eleveld, A. van Veen. Void growth and thermal desorption of deuterium from voids in tungsten. J. Nucl. Mater. 212, 1421 (1994).

43. R. Sakamoto, T. Muroga, N. Yoshida. Microstructural evolution induced by low energy hydrogen ion irradiation in tungsten. J. Nucl. Mater. 220, 819 (1995).

44. S. O'hira, A. Steiner, H. Nakamura, R. Causey, M. Nishi, S. Willms. Tritium retention study of tungsten using various hydrogen isotope irradiation. J. Nucl. Mater. 258, 990 (1998).

45. V.V. Kirsanov. Defects in Crystals and Their Computer Simulation (Nauka, 1980) (in Russian).

46. A. Debelle, P.-E. Lhuillie, M.-F. Barthe, T. Sauvage, P. Desgardin. Helium desorption in $3 \mathrm{He}$ implanted tungsten at low fluence and low energy. Nucl. Instrum. Meth. $B$ 268, 223 (2010).

Received 21.11.18.

Translated from Ukrainian by O.I. Voitenko 
В.В. Бобков, Л.П. Тищенко,

Ю.І. Ковтуненко, Р.І. Старовойтов, Ю.Є. Логачов,

О.Б. Цапенко, Л.О. Гамаюнова

ІМПЛАНТАЦІЯ ІОНІВ ДЕЙТЕРІЮ

ТА ГЕЛІЮ У КОМПОЗИЦІЙНУ СТРУКТУРУ З ВОЛЬФРАМОВИМ ПОКРИТТЯМ

Р е $з$ ю м е

Досліджено захоплення, утримання та термодесорбцію іонно-імплантованих дейтерію та гелію, утворення радіа- ційних пошкоджень кристалічної гратки вольфрамових покриттів багатошарових функціональних структур, опромінених іонами $\mathrm{D}^{+}$та $\mathrm{He}^{+}$середніх енергій. Дослідження проведено за допомогою методів термодесорбційної спектрометрії та електронної мікроскопії. Поведінку дейтерію та гелію у матеріалах вивчали в залежності від температури постімплантаційного нагріву, дози опромінення іонами $\mathrm{He}^{+}$та $\mathrm{D}^{+}$і умов опромінення іонами: індивідуальне або послідовне. Запропоновано типи утворюваних радіаційних дефектів та механізми їх відпалу. 